Forty seven genera of lichens were identified, out of them ten genera are sensitive to air pollutants. The highest atmospheric $\mathrm{SO}$, and $\mathrm{NO}$, levels $\left(48.35 \mu \mathrm{g} / \mathrm{m}^{3}\right.$ and $\left.42.825 \mu \mathrm{g} / \mathrm{m}^{3}\right)$ as well as the lowest lichen diversity $(0.8374)$ were recorded from the site located in Colombo Fort. When land use pattern changed from village to urban and with increase of traffic density of sites, diversity of lichens reduced significantly. The relationship between diversity of lichens and levels of $\mathrm{SO}_{2}$ and $\mathrm{NO}_{2}$ was negatively correlated but significant only with levels of $\mathrm{NO}$, Further, a significant negative correlation was found between the $\mathrm{pH}$ of substrates and levels of $\mathrm{SO}$, and $\mathrm{NO}$. Principal component analysis revealed that principal component $1(\mathrm{PC} 1), \mathrm{PC} 2$ and $\mathrm{PC} 3$ explain $38 \%, 20 \%$ and $15 \%$ of the total variation in the data set respectively. Biplot developed by $\mathrm{PCl}$ vs $\mathrm{PC} 2$ revealed that low lichen diversity class is clearly separated from other classes due to increased concentrations of $\mathrm{SO}_{2}, \mathrm{NO}_{2}$ land use pattern and the traffic density, all of which are included in PC1. Bark pH values of Cócos nucifera and Artocarpus heterophyllus that are represented by $\mathrm{PC} 2$ also had contributed to above grouping. Index of atmospheric purity (IAP) values increased along all transect with gradual decrease of $\mathrm{SO}_{2}$ and $\mathrm{NO}_{2}$ levels when moving away from the city.

Absence of several pollutant sensitive tropical lichens and decrease of lichen diversity in sites with high levels of $\mathrm{SO}_{2}$ and $\mathrm{NO}_{2}$, indicate that tropical lichens have the potential to be used as indicators in air pollution monitoring work.

\title{
059 \\ Emission factors for selected PAHs and carbonyl compounds from locally available mosquito coils and joss stick brands
}

\author{
L C Kalutarage and K R R Mahanama \\ Department of Chemistry, University of Colombo, Sri Lanka
}

In recent years, numerous investigations have revealed that indoor air pollution has a subtle chemistry which produces a range of pollutants. Combustion sources (some of which can be eradicated from indoors) have become the major contributor to the indoor air pollution and the pollutants emanating from these sources can poses serious health threats. Two of the combustion sources which can be eliminated from indoor settings, burning mosquito coils and joss sticks, were investigated in this study with the emphasis on the einissions of the carbonyl compounds and polycyclic aromatic hydrocarbons [PAHs].

Both carbonyl compounds and PAHs are known health hazards which are ubiquitous in the indoors due to incomplete combustion of organic compounds as well as due to the off gassing from consumer products. Poor air circulations entrap the pollutants indoors elevating the exposure and hence the health risks. Seven mosquito coil brands (locally made) and eight joss stick brands (both locally and Indian made) were burned in a laboratory setting simulating the indoor conditions. All the smoke emanating from the combustion source was passed through a prototype sampler. The volatile carbonyl compounds were derivatized to non-volatile 2,4-dinitrophenyl hydrazones and PAHs were collected separately using methanol. The hydrazone derivatives of the carbonyl compounds and the PAHs were separated individually using reversed-phase HPLC and quantified using UV and fluorescence detectors respectively.

The average emission factors for mosquito coils were $266 \pm 114 \mu \mathrm{g} \mathrm{g}^{-1}$ (formaldehyde), $94 \pm 37 \mu \mathrm{g} \mathrm{g}$. 1 (acetaldehyde) and $67 \pm 13 \mu \mathrm{g} \mathrm{g}^{-1}$ (acetone) compared to that of joss sticks $127 \pm 18 \mu \mathrm{g}$ g. '(formaldehyde), $38 \pm 11 \mu \mathrm{g} \mathrm{g}^{-1}$ (acetaldehyde) and $38 \pm 11 \mu \mathrm{g} \mathrm{g}^{-1}$ (acetone). The levels of acrolein, crotonaldehyde and propanaldehyde were very low and they could not be quantified with significant accuracy and precision.

The emission factors for naphthalene, acenapthene, acenapthylene, fluorine, phenanthrene, anthracene, fluoranthene, pyrene, benzo[a] anthracene, chrysene, benzo[b]fluoranthene, benzo[k]fluoranthene and benzo[a]pyrene were $6.33 \pm 1.00,9.45 \pm 1.04,2.44 \pm 0.47,6.54 \pm 0.54,9.07 \pm 0.55,3.96 \pm 0.98,4.63$ $\pm 0.44,0.64 \pm 0.17,1.52 \pm 0.42,2.67 \pm 0.66,0.25 \pm 0.08,0.21 \pm 0.05$ and $0.17 \pm 0.15 \mu g^{-1}$ respectively for mosquito coils and the emission factors of joss sticks for the same compounds were $5.33 \pm 0.94$, $7.80 \pm 0.95,2.14 \pm 1.14,4.25 \pm 1.04,4.79 \pm 0.66,3.53 \pm 0.42,5.04 \pm 0.99,0.44 \pm 0.12,1.14 \pm 0.17$, $1.63 \pm 0.63,0.18 \pm 0.04,0.23 \pm 0.15$ and $0.15 \pm .06 \mu \mathrm{g} \mathrm{g}-1$ respectively. 
In general, Indian joss stick brands emitted more PAHs and carbonyl compounds compared to the local brands. This research is an attempt to glance at the exposures which can be prevented through simple measures such as controlling the indoor combustions.

\title{
060 \\ Low cost eco-friendly polyethylene film for packaging of wheat flour
}

\author{
S Liyanage and A A R Amarasinghe \\ Department of Chemistry, University of Sri Jayewardenepura, Sri Lanka.
}

\begin{abstract}
At present polymer packaging industry is compelled to use PET based polymeric materials to manufacture packaging materials for food packaging including wheat flour. Though these PET based materials possess the required properties these materials are very expensive and non recyclable. Therefore many researchers are investigating the possibilities of manufacturing polyethylene based packaging materials, which are eco-friendly to replace expensive PET based materials.
\end{abstract}

In this study an effort was made to identity good quality low cost eco-friendly products for packaging of wheat flour. The trials were carried out using different blends of LLDPE, LPDE and high molecular weight PE. In this study packaging materials were produced using the multi-layer co-extrusion technique. Both field trials and laboratory trials were used to analyze the samples. As the most efficient packaging system for flour is form-fill seal machine system, prepared samples was sent to packaging plants to check whether the sample was able to reach the required runability at form-fill seal machine. The physical properties such as tensile strength tear strength and puncture resistance were measured. Depend on observed values PE blends were gauging down to minimum tolerance limit to contain up to $1 \mathrm{~kg}$ relative dense products. The Water Vapor Transmission Rate (WVTR) of the film also measured because the shelf life of wheat products very heavily depends on its water activity. Finally a low cost eco-friendly PE based packaging material for wheat flour was developed.

\section{$\underline{061}$ \\ Eutrophication and poultry industry: Issues, challenges and opportunities \\ N S B M Atapattu \\ Department of Animal Science, University of Ruhuna, Sri Lanka.}

Eutrophication is the process of excessive growth of algae and cynobacteria due to over enrichment of the surface waters with mineral nutrients. Eutrophication restricts water use for fisheries, recreation, industry and drinking. Phosphorus $(\mathrm{P})$ is the limiting mineral for the eutropication process. Experience from America, Europe and Australia clearly shows that improper land application of poultry litter is among the main contributors of eutrophication process. Poultry utilizes dietary phosphorus rather inefficiently, due mainly to high level of phytate in their diets and, low intrinsic phytase activity both in poultry and plant materials. Phytates increase the excretion of $\mathrm{N}$ and a range of other cations and, thus increases the eutrophic potential of poultry litter. Poultry industry of Sri Lanka expanded dramatically during the last few decades and it has been predicted that the growth will continue. Meanwhile, use of poultry litter as an organic fertilizer is becoming popular, particularly in up country cropping systems. The risk of getting water bodies eutrophicated due to the present trend of indiscriminate land application of poultry litter in up country cropping systems is tremendous. Estimated minimum annual $P$ output from local poultry industry is around 751.8 metric tonnes. Decreasing the $P$ level in faeces through dietary manipulations is probably the most cost-effective and practical approach to reduce the $\mathrm{P}$ losses to the environment. In poultry ration formulation, the requirement of $\mathrm{P}$ is expressed as the non-phytate P requirement. No upper limits have been set for the total P level in the diet. This has given the liberty to the feed industry to use poorly digestible plant $\mathrm{P}$ sources in the diets. From environmental point of view, it is important to set maximum total $\mathrm{P}$ levels for poultry diets. Supplementation of poultry diets with microbial phytases can reduce the faecal P levels by about $30 \%$ and also faecal $\mathrm{N}$ and other cation levels. Regulatory mechanisms should be imposed to make the use of phytase compulsory, at least when the total dietary P levels exceed a particular limit. A range of chemical and physical means are also available to increase the $\mathrm{P}$ utilization in poultry. Both farmers and the feed industry should be encouraged to adopt those strategies. A maize variety with reduced

Proceedings of the International Forestry and Environment Symposium 2006 of the

Department of Forestry and Environmental Science. University of Sri Jayewardenepura, Sri Lanka 